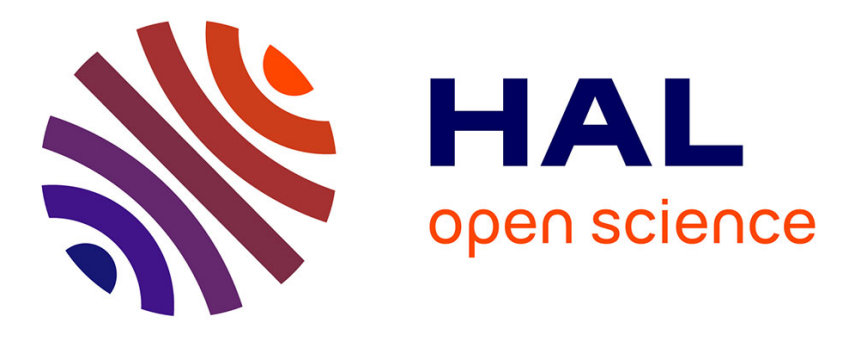

\title{
Nondestructive evaluation of forced delamination in glass fiber-reinforced composites by terahertz and ultrasonic waves
}

Junliang Dong, Byungchil Kim, A. Locquet, Peter Mckeon, Nico Declercq, D.S. Citrin

\section{To cite this version:}

Junliang Dong, Byungchil Kim, A. Locquet, Peter Mckeon, Nico Declercq, et al.. Nondestructive evaluation of forced delamination in glass fiber-reinforced composites by terahertz and ultrasonic waves. Composites Part B: Engineering, 2015, 79, pp.667-675. 10.1016/j.compositesb.2015.05.028 . hal-03079427

\section{HAL Id: hal-03079427 \\ https://hal.science/hal-03079427}

Submitted on 17 Dec 2020

HAL is a multi-disciplinary open access archive for the deposit and dissemination of scientific research documents, whether they are published or not. The documents may come from teaching and research institutions in France or abroad, or from public or private research centers.
L'archive ouverte pluridisciplinaire HAL, est destinée au dépôt et à la diffusion de documents scientifiques de niveau recherche, publiés ou non, émanant des établissements d'enseignement et de recherche français ou étrangers, des laboratoires publics ou privés. 
Nondestructive evaluation of forced delamination in glass fiber-reinforced composites by terahertz and ultrasonic waves

Junliang Dong, ${ }^{\mathrm{a}, \mathrm{b},{ }^{*}}$ Byungchil Kim, ${ }^{\mathrm{a}, \mathrm{b}}$ Alexandre Locquet, ${ }^{\mathrm{a}, \mathrm{b}}$ Peter McKeon, ${ }^{\mathrm{a}}$ Nico Declercq, ${ }^{\mathrm{a}, \mathrm{c}} \quad$ D.S. Citrin ${ }^{\mathrm{a}, \mathrm{b}, *}$

${ }^{a}$ Georgia Tech-CNRS UMI2958, Georgia Tech Lorraine, 2 rue Marconi, 57070 Metz, France

${ }^{\mathrm{b}}$ School of Electrical and Computer Engineering, Georgia Institute of Technology, Atlanta, Georgia 30332 USA

${ }^{c}$ Woodruff School of Mechanical Engineering, Georgia Institute of Technology, Atlanta, Georgia 30332 USA

Corresponding authors:

Junliang Dong Email: junliang.dong@gatech.edu

D. S. Citrin Email: $\underline{\text { david.citrin@ece.gatech.edu }}$

Tel: $+33(0) 38720-1165$ 


\begin{abstract}
:
Glass fiber-reinforced composite laminates in polyetherimide resin have been studied via terahertz imaging and ultrasonic $\mathrm{C}$-scans. The forced delamination is created by inserting Teflon film between various layers inside the samples prior to consolidating the laminates. Using reflective pulsed terahertz imaging, we find high-resolution, low-artifact terahertz C-scan and B-scan images locating and sizing the delamination in three dimensions. Furthermore, terahertz imaging enables us to determine the thicknesses of the delamination and of the layers constituting the laminate. Ultrasonic C-scan images are also successfully obtained; however, in our samples with small thickness-to-wavelength ratio, detailed ultrasonic B-scan images providing quantitative information in depth cannot be obtained by $5 \mathrm{MHz}$ or $10 \mathrm{MHz}$ focused transducers. Comparative analysis between terahertz imaging and ultrasonic $\mathrm{C}$-scans with regard to spatial resolution is carried out demonstrating that terahertz imaging provides higher spatial resolution for imaging, and can be regarded as an alternative or complementary modality to ultrasonic C-scans for this class of glass fiber-reinforced composites.
\end{abstract}

Keywords: D. Non-destructive testing
A. Polymer-matrix composites (PMCs)
B. Delamination
D. Ultrasonics
Terahertz imaging 


\section{Introduction}

Fiber-reinforced composites provide an alternative to conventional structural materials such as concrete, steel, aluminum, and wood. Used for structural purposes, fiber-reinforced composites have the advantage of combining a number of properties not usually found together in a single material. In particular they combine high strength and low weight, while at the same time they may be resistant to corrosion and have thermal and electrical insulation properties. As a result, the wide applicability of fiber-reinforced composites has created the need for correspondingly advanced nondestructive evaluation (NDE) techniques for inspection and failure detection during manufacturing and maintenance.

Various NDE techniques capable of characterizing damage and defects in fiber-reinforced composites have been developed. Among them, ultrasonic testing is the most well-known tool to characterize fiber composites, including ultrasonic C-scans [1-3], ultrasonic polar scans [4-5], nonlinear ultrasonics [6], and guided-wave inspection [7-8]. However, until now, only the ultrasonic C-scan technique has found widespread implementation in industry, because of simplicity of analysis and its effectiveness in geometrically locating damage and defects. In ultrasonic C-scans, the ultrasonic waves show specific transmission and reflection features depending on the spatial variation of acoustic impedance within the fiber-reinforced composite. Ultrasonic C-scans can provide a good trade-off between material penetration and measurement resolution, and ultrasonic C-scans in pulse-echo mode can also provide qualitative information in depth 
for thick fiber composite samples [9].

Because of certain limitations associated with ultrasonic C-scans (see below), there is growing interest in alternative imaging modalities and NDE techniques, such as shearography, IR thermography, and X-ray radiography, to name a few. Considerable work has been carried out to compare such approaches with ultrasonic C-scans, which stands as the reference standard for NDE in these materials [10-15]. These comparisons highlight some of the difficulties associated with the ultrasonic C-scan technique in these materials: (1) negligible quantitative information in depth can be obtained in thin samples with small thickness-to-wavelength ratio due to the relatively large time duration of ultrasonic pulse signal; (2) because of the attenuation of ultrasonic waves in fiber-reinforced composites (especially in glass fiber-reinforced composites), the operating frequency cannot be sufficiently high (usually less than $10 \mathrm{MHz}$ ) [16], thus limiting the resolution; and (3) liquid coupling may be required. Although contactless ultrasonic techniques using laser [17, 18] and air-coupled transducers [19] have been proposed, problems (1) and (2) remain. Therefore, alternative nondestructive, noncontact, and nonionizing (to minimize health risks) techniques with relatively high resolution are still needed for inspection of fiber-reinforced composites.

As an alternative to ultrasonic waves, we here investigate the use of terahertz-frequency electromagnetic waves. The terahertz $(\mathrm{THz})$ portion of the electromagnetic spectrum extends from approximately $100 \mathrm{GHz}$ to $10 \mathrm{THz}$, and lies between the microwaves and infrared; the wavelength range in this region is $3 \mathrm{~mm}$ 
down to $3 \mu \mathrm{m}$. THz waves can penetrate numerous nonmetallic materials that may be opaque in the range of visible and infrared light [20]. Moreover, as nonionizing radiation, THz waves present minimal known health risks [21]. Due to these remarkable properties of $\mathrm{THz}$ wave, THz imaging was firstly introduced to NDE of fiber-reinforced composites in 2006 [22], and has already become a new promising tool nowadays [23]. For carbon fiber-reinforced composites, due to the conductivity of carbon fiber [24], $\mathrm{THz}$ waves have to date only been demonstrated to detect the defects near the surface of the material or in the coating material on a carbon fiber substrate $[25,26]$. For glass fiber-reinforced composites, $\mathrm{THz}$ waves can penetrate further to detect buried and underlying defects, including voids, delamination, and intrusions [27-31]. THz waves can also been used to detect the fiber content and orientation inside glass fiber-reinforced composites [32, 33].

In the present study, we carry out both $\mathrm{THz}$ imaging and ultrasonic $\mathrm{C}$-scans of glass fiber-reinforced composite laminates in polyetherimide resin with delaminations. The defects are created by inserting Teflon film between various layers inside the samples prior to consolidating the laminates. Based on the results, we conclude that $\mathrm{THz}$ imaging can provide a nondestructive, noncontact, and nonionizing method to evaluate glass fiber-reinforced composites with higher spatial resolution, and can be regarded as an alternative or complimentary to ultrasonic C-scans. We point out, moreover, the most important merit of $\mathrm{THz}$ imaging is the ability of providing quantitative information in depth and three-dimensional imaging of the samples. 


\section{Samples and Experiment Setup}

Eight-harness-stain fabric glass fiber reinforced polyetherimide matrix laminates, shown in Fig. 1(a), are employed in the experiment. The samples contain eight layers with a total thickness of $1.85 \mathrm{~mm}$, and the fiber volume fraction is about 50 vol.\%. Two different circular sizes of defects with diameters $6 \mathrm{~mm}$ and $12 \mathrm{~mm}$ were intentionally introduced by adding release Teflon-film disks, with thickness approximately $250 \mu \mathrm{m}$, to create forced delamination. 64 samples were obtained by cutting the laminate from as fabricated $42 \mathrm{~cm}$ x $42 \mathrm{~cm}$ sheet down to $5 \mathrm{~cm}$ x $5 \mathrm{~cm}$ pieces, as shown in Fig. 1(b). Defects are spread throughout the laminate, so that most of the samples have one or two defects, and some have none; however, no samples had delamination visible at the edge nor was the delamination visually apparent or detectible by thickness variation measured by calipers. The defects are inserted between various layers. All samples presented the same visual appearance and possessed the same overall structure (apart from the delaminations).

We employ a pulsed, broadband THz time-domain spectroscopy (TDS) system [22], shown schematically in Fig.2. The GaAs photoconductive antenna is excited by an ultrafast (femtosecond) laser to produce roughly single-cycle $\mathrm{THz}$ pulses with bandwidth extending from $60 \mathrm{GHz}$ to $3 \mathrm{THz}$ (corresponding wavenumbers $2 \mathrm{~cm}^{-1}$ to $\left.100 \mathrm{~cm}^{-1}\right)$. The ultrafast laser used in our system is an Er-doped fiber laser that emits $780 \mathrm{~nm}$ pulses with sub-100 femtosecond pulse duration at a repetition rate of $100 \mathrm{MHz}$ 
and has an average output power in excess of $65 \mathrm{~mW}$. Coherent detection of the $\mathrm{THz}$ radiation is performed in a similar photoconductive antenna circuit. By gating the photoconductive gap with a femtosecond pulse synchronized to the terahertz emission, a current proportional to the terahertz electric field is measured. By varying the optical path length, the THz time domain can be sampled, resulting in both amplitude and phase information. By taking the Fourier transform, spectroscopic information can be obtained. The power of the $\mathrm{THz}$ radiation used for the measurement is below $1 \mu \mathrm{W}$, so no thermal strain is induced in the sample.

Both reflection and transmission imaging can be performed in our system. The sample is raster-scanned by a set of motorized stages moving in $\mathrm{X}$ and $\mathrm{Y}$ directions, which similar to common ultrasonic C-scan equipment. The amplitude and phase of the $\mathrm{THz}$ pulse transmitted or reflected through the sample is measured. Refractive-index discontinuities as a function of depth produce multiple reflections off the various associated interfaces between laminae. These reflections are manifested in the transmitted or reflected pulse containing several peaks at corresponding time delays. By analyzing these peaks together with knowledge of the refractive indices of the constituents, we can reconstruct the sequence and thicknesses of the various laminae.

\section{Terahertz Imaging Results}

$\mathrm{THz}$ C-scan (i.e., across the $50 \mathrm{~mm}$ x $50 \mathrm{~mm}$ surface) image of sample 1 in reflection is shown in Fig. 3(a). The image is acquired with a $0.1 \mathrm{~mm}$ spatial step size over the image domain. The contrast mechanism chosen for this image is the difference 
between the maximum and minimum values of the reflected $\mathrm{THz}$ pulse in a selected time slice between 13 ps to 20 ps. This was chosen to maximize contrast between regions containing delamination and regions without delamination. The $\mathrm{THz}$ pulse encountering a region containing a delamination leads to higher difference between the maximum and minimum reflected amplitude in the relevant time window due to the higher difference of the refractive index, which corresponds to the lighter two circular regions in Fig. 3(a) compared with the surrounding regions. We apply one common approach, the so-called $50 \%$ rule or $-6 \mathrm{~dB}$ drop method, to estimate the size of the delamination $[34,35]$. This method locates the pixel with the highest value in the C-scan image and assigns this a value of $100 \%$, then colors all pixels red that have a value of at least $50 \%$ of the maximum. Fig. 3(b) shows the C-scan image after applying this method. Given this procedure, we can determine the area of the circular regions associated with delamination. The area of the larger circular region is $106.96 \mathrm{~mm}^{2}$, corresponding to a Teflon disk with diameter $12 \mathrm{~mm}$ (equivalent area: $113.10 \mathrm{~mm}^{2}$ ); the area of the small circular region is $25.88 \mathrm{~mm}^{2}$, corresponding to a Teflon disk with diameter $6 \mathrm{~mm}$ (equivalent area: $28.27 \mathrm{~mm}^{2}$ ). The dimension of $\mathrm{THz}$ focal spot mainly determines the accuracy of sizing the delamination. Diffraction effects at the edge of the Teflon film may also be responsible for the errors of sizing the delamination in our C-scan images.

THz B-scan images in Fig. 4(a) and (b) provide depth information along sections [labeled Cut 1 and Cut 2 in Fig. 3(a)] through the two delaminations. Eight layers can 
be clearly identified. The narrow bright band near an optical delay of 10 ps coincides with the top surface of the sample on the side of the incident $\mathrm{THz}$ pulses. The localized lighter bands between resin layers 2 and 3 (optical delay $\sim 16 \mathrm{ps)} \mathrm{correspond} \mathrm{to} \mathrm{the}$ depth locations of the delaminations. Besides these two-dimensional imaging results, three-dimensional $\mathrm{THz}$ imaging produces end results similar to $\mathrm{THz}$ tomography [36, 37], though the later typically employs back projection techniques and the Radon transform, which we do not do. Fig. 5 shows the three-dimensional THz image of the sample which clearly exhibits the locations of the delaminations.

Various features that appear in B-scans of Fig. 4(a) and (b) can be illustrated by the temporal data associated with reflected THz pulses. In Fig. 6 are shown raw THz signals (electric field as a function of time) obtained from $x, y$ regions absent or containing delaminations with layer information indicated by the various colors. The largest peak in all cases corresponds to the THz pulse reflected off the surface of the sample 1 on the side from which the THz pulses were incident. In Fig. 6(a) are data obtained from a delamination-free region for clarity. The various subsidiary peaks at optical delay $>10$ ps correspond to pulses that have bounced back off various interfaces between resin layers [38]. Figure 6(b) shows the reflected $\mathrm{THz}$ pulse from a representative point in a delaminated region with the same data as in Fig. 6(a) for reference. The most notable new features are the two enhanced peaks appearing between the second and third lamina (optical delays $15.8 \mathrm{ps}$ and $18.2 \mathrm{ps}$ ). These two enhanced peaks indicate the location of the Teflon film due to the relatively large refractive index mismatch between the resin 
and Teflon. Because of this inserted Teflon film, lamina 3 is deformed and the corresponding peak in the time-domain $\mathrm{THz}$ signal is shifted to a larger optical delay. At later optical delays, the features in the region of delamination are similar to those in the delamination-free region. However, lamina 4 to 8 are compressed due to the fabricating process after adding the Teflon film, which ensured a uniform overall thickness of the entire laminate.

A detailed investigation of the data in Fig. 6 provides quantitative information on the lamina and delamination thicknesses. In our case, these distinguishable reflected signals characterized by their optical delays in conjunction with the refractive indices of the constituent materials enable us to identify layer thicknesses and locations. For the cases with overlapping echoes, measurement of thicknesses can also be conducted based on the integration of time-domain waveforms mentioned in [39]. Because we can measure both the amplitude and the phase of the transmitted $\mathrm{THz}$ pulses (not shown), we can extract the index of refraction of the sample across the $\mathrm{THz}$ band, which varies little in this range and has the value of 2.16 in the frequency range from $0.3 \mathrm{THz}$ to 1.3 THz. Hence, we can calculate the thickness of any single resin layer; for example, the thickness of layer 1 is $L_{\text {layer }}=\frac{\Delta t^{\prime}}{2} \frac{c}{n_{P E I}} \approx 229 \mu \mathrm{m}$

where $c$ is the in-vacuo speed of light, $\Delta t^{\prime}=3.3 \mathrm{ps}$ is the time between successive reflections, and the factor of one half arises since in reflection, the pulse passes through any given layer twice. We thus obtain a total sample thickness of 
$L_{\text {sample }}=\frac{\Delta T}{2} \frac{c}{n_{P E I}} \approx 1.83 \mathrm{~mm}$,

close to the actual value of $1.85 \mathrm{~mm}$. Similarly, using the published values of the Teflon refractive index 1.45 [40] and the time delay $\Delta t=2.4 \mathrm{ps}$ between the reflections associated with the interfaces between the Teflon and the adjoining polyetherimide layers, we can calculate the thickness of the Teflon film,

$$
L_{\text {Teflon }}=\frac{\Delta t}{2} \frac{c}{n_{\text {Teflon }}} \approx 248 \mu \mathrm{m}
$$

again, quite close to the value of $250 \mu \mathrm{m}$ of the inserted Teflon film.

Table 1. Representative $\mathrm{THz}$ imaging results. $12 \mathrm{~mm}$ and $6 \mathrm{~mm}$ refer to Teflon disk dameters.

\begin{tabular}{|c|c|c|}
\hline Sample Number & Defect Type & Defect Location \\
\hline 23 & Two $12 \mathrm{~mm}$ & Between Layer 2 and 3 \\
\hline 10 & One $12 \mathrm{~mm}$ and one $6 \mathrm{~mm}$ & Between Layer 3 and 4 \\
\hline 60 & One $12 \mathrm{~mm}$ and one $6 \mathrm{~mm}$ & Between Layer 4 and 5 \\
\hline 46 & One $12 \mathrm{~mm}$ and one $6 \mathrm{~mm}$ & Between Layer 5 and 6 \\
\hline 51 & One $6 \mathrm{~mm}$ & Between Layer 6 and 7 \\
\hline 57 & One $12 \mathrm{~mm}$ & Between Layer 7 and 8 \\
\hline
\end{tabular}

We obtained $\mathrm{THz}$ images of all 64 samples, and we have in all cases identified the delaminations and have measured the thicknesses of the lamina and Teflon film disks. Representative results based on our THz images on samples with various defect patterns are shown in Table 1 corresponding to the C-scans, B-scans, and time domain waveforms are shown in Fig. 7. From the detailed analysis plus the results shown in Fig. 7, we conclude that $\mathrm{THz}$ imaging can provide low-artifact images (time domain $\mathrm{C}$-scan and B-scan) - and thus three-dimensional information-as well as quantitative 
information on delamination in glass fiber-reinforced composite laminates.

\section{Ultrasonic Imaging Results}

A customer-designed ultrasonic scanner fabricated by Inspection Technology Europe BV is used for ultrasonic C-scan experiment. The transducer chosen for this investigation is a focused-immersion transducer with a manufacturer-provided central frequency of $5 \mathrm{MHz}$ considering both the attenuation and resolution. Ultrasonic C-scans were performed on the samples with water coupling under both transmission (pitch-catch) mode and reflection (pulse-echo) mode over an area of $25 \mathrm{~mm}$ x $25 \mathrm{~mm}$ with a $0.1 \mathrm{~mm}$ scan step size in order to keep the same pixel size as the one we set in $\mathrm{THz}$ imaging.

Figure 8 shows the ultrasonic C-scan images for samples 51 and 57 in both transmission and reflection, showing that ultrasonic C-scans can also successfully identify the delamination areas. The contrast for ultrasonic C-scan images are based on the absolute value of the amplitude of the ultrasonic transmitted or reflected wave. The typical transmitted and reflected waveforms obtained with and without the delamination are compared in Fig. 9. Note the much larger timescale of the ultrasound pulses versus the THz pulses. In the transmission mode shown in Fig. 9(a), the transmitted waveform in the windowed time slice is chosen to provide sharper contrast for the ultrasonic C-scan images, because this transmitted waveform traverses the samples three times. In the reflection mode shown in Fig. 9(b), the second echo, which is also in the windowed time slice, is chosen to obtain the ultrasonic C-scan images, since the first echo is 
mainly the specular reflection from the sample surface.

Again, we again apply the $50 \%$ rule for sizing the delamination in the ultrasonic $\mathrm{C}$-scan images, and we regard the pixels with values below the $50 \%$ of the maximum as the delamination area in this case. Results for sizing the delaminations with the $50 \%$ rule are shown in Fig. 10. The different sizing results between transmission and reflection mode can most likely be attributed to using the focused transducers. Factors including the finite dimensions of the focal point of ultrasonic transducer, diffraction effects at the edge of the defects and alignment errors of the transducers should be considered for the errors of sizing the delamination.

With the ultrasonic waveforms in reflection mode, we can also obtain the ultrasonic B-scan images, shown in Fig. 11. In the B-scan images, we still clearly see the delamination region and can roughly locate the delamination in depth. Four signal peaks can be observed between the echoes from the top and bottom of the sample. However, unlike the $\mathrm{THz}$ B-scan images, these four peaks cannot be identified as the layers in the samples. Overlapping echoes coming from the top surface, the bottom surface and the interfaces between different layers and delaminations cause the local maximums in the signal making it difficult to identify the laminae and the delaminations inside the samples from the ultrasonic B-scan images.

\section{Comparison and Discussion}

Comparison between $\mathrm{THz}$ imaging and ultrasonic C-scans can be performed with 
respect to the spatial resolution of images obtained from both cases. Spatial resolution contains two parts: lateral and axial resolution.

Lateral resolution is the minimum distance that can be differentiated between two point scatters across the scan plane. The lateral resolution is high when the focal spot size of the beam is small. For $\mathrm{THz}$ imaging, the focal spot size of $\mathrm{THz}$ beam is frequency dependent, the higher the frequency, the smaller the spot size. In our $\mathrm{THz}$ TDS system, the lateral resolution at the surface is about $0.3 \mathrm{~mm}$ at $1 \mathrm{THz}$. For ultrasonic C-scans, lateral resolution is $1.95 \mathrm{~mm}$ for our focused transducers at $5 \mathrm{MHz}$. Therefore, THz imaging can achieve higher lateral resolution than ultrasonic C-scans, which can be corroborated by the comparison between the results of sizing the delamination by both techniques in Fig. 3 and 10 . THz imaging can provide more accurate results of sizing the delamination than ultrasonic C-scans, especially for the small delamination.

Axial resolution is the minimum distance that can be differentiated between two points in depth. Axial resolution is equal to half the spatial pulse length; it is high when the spatial pulse length is short. For $\mathrm{THz}$ imaging, the axial resolution $d$ is determined by

$d=\frac{c \cdot \Delta T_{w}}{2 n_{P E I}}$

where $\Delta T_{w}$ is the temporal width of the THz pulse. The axial resolution in our THz TDS system is estimated to be about $45 \mu \mathrm{m}$ with $\Delta T_{w}=0.65 \mathrm{ps}$. For ultrasonics, the spatial pulse length is equal to the product of the number of cycles in a pulse and the 
wavelength. The acoustic wavelength at a frequency of $5 \mathrm{MHz}$ is about $500 \mu \mathrm{m}$ in our glass fiber-reinforced composite samples. The different axial resolution can also be identified from $\mathrm{THz}$ and ultrasonic waveforms, shown in Figs. 6 and 9. As mentioned before, we can clearly identify the various time-domain features associated with the $\mathrm{THz}$ pulse encountering each lamina interface as well as the delamination. By contrast, the timescale of ultrasonic pulses are quite different. The relatively long time duration of ultrasonic pulse leads to overlapping echoes in the small thickness-to-wavelength ratio samples and makes it difficult if not impossible to clearly identify features on the length scale of the laminae thickness and delamination. The fundamental point is that the ultrasonic axial resolution is not sufficient to obtain detailed B-scan images in our case. Employing considerably higher acoustic frequencies with shorter wavelength would seem to improve the axial resolution. Therefore, a $10 \mathrm{MHz}$ focused-immersion transducer was used to provide a shorter wavelength, but the attenuation in this frequency range is prohibitively high in the samples, which in turn led to no discernible second echo signal in reflection.

Therefore, $\mathrm{THz}$ imaging can provide higher spatial resolution than the ultrasonic C-scan technique for imaging our glass fiber-reinforced composite samples. Ultrasonic axial resolution is not sufficient to provide the quantitative information in depth for us to identify the number of laminae nor the thickness of the delamination.

\section{Conclusions}

In this study we have systematically carried out $\mathrm{THz}$ imaging and ultrasonic C-scan of 64 eight-layered glass fiber-reinforced composite samples based on polyetherimide resin. Using $6 \mathrm{~mm}$ and $12 \mathrm{~mm}$ circular pieces of $250-\mu \mathrm{m}$ thick Teflon film, zero, one, or two delaminated regions were introduced in each sample between 
various layers. $\mathrm{THz}$ imaging successfully located all delaminations without prior knowledge of their presence or location in various samples. In addition to locating and sizing the delaminations in the $\mathrm{C}$-scans with high resolution, quantitative depth information was also obtained by B-scans. Moreover, THz imaging does not involve coupling medium, and therefore may be more convenient in some contexts.

Comparisons between $\mathrm{THz}$ imaging and ultrasonic $\mathrm{C}$-scans were also carried out based on the analysis of spatial resolution. THz imaging can provide higher lateral resolution for sizing the delamination, and higher axial resolution for the identification of the depth of a delamination quantitatively. Ultrasonic C-scans suffers from overlapping echoes in our samples due to the relatively low axial resolution. Considering the high attenuation in glass fiber composites, which only becomes worse at higher frequencies, a good balance between material penetration and resolution is also difficult to achieve in samples with small thickness-to-wavelength ratio. For these types of samples, $\mathrm{THz}$ imaging, which can provide a nondestructive, noncontact, and nonionizing method to evaluate glass fiber-reinforced composites, can be utilized as an alternative or complementary modality to ultrasonic C-scans.

\section{Acknowledgment}

The authors acknowledge R. Bergman of Ten Cate Advanced Composites BV for kindly supplying the samples in this study and for helpful discussions. The authors also acknowledge the support of the Region of Lorraine.

\section{REFERENCES}


[1] Harizi W, Chaki S, Bourse G, Ourak M. Mechanical damage characterization of glass fiber-reinforced polymer laminates by ultrasonic maps. Composites Part B: Engineering. 2015;70(0):131-7.

[2] El-Sabbagh A, Steuernagel L, Ziegmann G. Characterisation of flax polypropylene composites using ultrasonic longitudinal sound wave technique. Composites Part B: Engineering. 2013;45(1):1164-72.

[3] Smith RA, Nelson LJ, Mienczakowski MJ, Challis RE. Automated analysis and advanced defect characterisation from ultrasonic scans of composites. Insight-Non-Destructive Testing and Condition Monitoring. 2009;51(2):82-7.

[4] Kersemans M, De Baere I, Degrieck J, Van Den Abeele K, Pyl L, Zastavnik F, et al. Nondestructive damage assessment in fiber reinforced composites with the pulsed ultrasonic polar scan. Polymer Testing. 2014;34(0):85-96.

[5] Declercq NF, Degrieck J, Leroy O. On the influence of fatigue on ultrasonic polar scans of fiber reinforced composites. Ultrasonics. 2004;42(1-9):173-7.

[6] Armitage PR, Wright CD. Design, development and testing of multi-functional non-linear ultrasonic instrumentation for the detection of defects and damage in CFRP materials and structures. Composites Science and Technology. 2013;87(0):149-56.

[7] Chakrapani SK, Dayal V. The interaction of Rayleigh waves with delaminations in composite laminates. The Journal of the Acoustical Society of America. 2014;135(5):2646-53.

[8] Leleux A, Micheau P, Castaings M. Long Range Detection of Defects in Composite 
Plates Using Lamb Waves Generated and Detected by Ultrasonic Phased Array Probes. J Nondestruct Eval. 2013;32(2):200-14.

[9] Amenabar I, Mendikute A, López-Arraiza A, Lizaranzu M, Aurrekoetxea J. Comparison and analysis of non-destructive testing techniques suitable for delamination inspection in wind turbine blades. Composites Part B: Engineering. 2011;42(5):1298-305.

[10] Kadlec M, Růžek R. A Comparison of Laser Shearography and C-Scan for Assessing a Glass/Epoxy Laminate Impact Damage. Appl Compos Mater. 2012;19(3-4):393-407.

[11] Gaudenzi P, Bernabei M, Dati E, De Angelis G, Marrone M, Lampani L. On the evaluation of impact damage on composite materials by comparing different NDI techniques. Composite Structures. 2014;118(0):257-66.

[12] Peronnet E, Eyma F, Welemane H, Mistou S. Characterization and comparison of defects detection limits of ultrasonic non destructive techniques. Key Engineering Materials. 2012;498:79-88.

[13] Liang C, Gui Yun T. Comparison of Nondestructive Testing Methods on Detection of Delaminations in Composites. Journal of Sensors. 2012;2012:1-7.

[14] Garnier C, Pastor M-L, Eyma F, Lorrain B. The detection of aeronautical defects in situ on composite structures using Non Destructive Testing. Composite Structures. 2011;93(5):1328-36.

[15] Dragan K, Swiderski W. Studying Efficiency of NDE Techniques Applied to 
Composite Materials in Aerospace Applications. Acta Physica Polonica A. 2010;117(5):878-83.

[16] Briotti G, Scarponi C. Acoustic Attenuation for Ultrasonic NDI Detection of Delaminations on Composite Laminates. Journal of Reinforced Plastics and Composites. 2001;20(1):76-87.

[17] Sun G, Zhou Z, Chen X, Wang J. Ultrasonic characterization of delamination in aeronautical composites using noncontact laser generation and detection. Applied Optics. 2013;52(26):6481-6.

[18] Karabutov AA, Podymova NB. Quantitative analysis of the influence of voids and delaminations on acoustic attenuation in CFRP composites by the laser-ultrasonic spectroscopy method. Composites Part B: Engineering. 2014;56(0):238-44.

[19] Imielińska K, Castaings M, Wojtyra R, Haras J, Clezio EL, Hosten B. Air-coupled ultrasonic C-scan technique in impact response testing of carbon fibre and hybrid: glass, carbon and Kevlar/epoxy composites. Journal of Materials Processing Technology. 2004;157-158(0):513-22.

[20] Mittleman D. Sensing with terahertz radiation / Daniel Mittleman, (ed.): Berlin ; New York : Springer, c2003.; 2003.

[21] Wilmink G, Grundt J. Current State of Research on Biological Effects of Terahertz Radiation. J Infrared Milli Terahz Waves. 2011;32(10):1074-122.

[22] Rutz F, Koch M, Khare S, Moneke M, Richter H, Ewert U. Terahertz Quality Control of Polymeric Products. J Infrared Milli Waves. 2006;27(4):547-56. 
[23] Amenabar I, Lopez F, Mendikute A. In Introductory Review to $\mathrm{THz}$ Non-Destructive Testing of Composite Mater. J Infrared Milli Terahz Waves. 2013;34(2):152-69.

[24] Im K-H, Hsu DK, Chiou C-P, Barnard DJ, Yang I-Y, Park J-W. Influence of terahertz waves on the fiber direction of CFRP composite laminates. AIP Conference Proceedings. 2013;1511(1):604-11.

[25] Bezborodov VI, Kiseliov VK, Kosiak OS, Kuleshov YM, Nesterov PK, Yanovsky MS. Quasi-optical sub-terahertz internal reflection reflectometer for non-destructive testing of carbon fiber reinforced plastics. Telecommunications and Radio Engineering. 2014;73(1):83-93.

[26] Yang S-H, Kim K-B, Oh HG, Kang J-S. Non-contact detection of impact damage in CFRP composites using millimeter-wave reflection and considering carbon fiber direction. NDT \& E International. 2013;57(0):45-51.

[27] Cristofani E, Friederich F, Wohnsiedler S, Matheis C, Jonuscheit J, Vandewal M, et al. Nondestructive testing potential evaluation of a terahertz frequency-modulated continuous-wave imager for composite materials inspection. Optical Engineering. 2014;53(3):031211-.

[28] Palka N, Miedzinska D. Detailed non-destructive evaluation of UHMWPE composites in the terahertz range. Opt Quant Electron. 2014;46(4):515-25.

[29] Ospald F, Zouaghi W, Beigang R, Matheis C, Jonuscheit J, Recur B, et al. Aeronautics composite material inspection with a terahertz time-domain spectroscopy 
system. Optical Engineering. 2013;53(3):031208-.

[30] Stoik CD, Bohn MJ, Blackshire JL. Nondestructive evaluation of aircraft composites using reflective terahertz time domain spectroscopy. NDT \& E International. 2010;43(2):106-15.

[31] Stoik CD, Bohn MJ, Blackshire JL. Nondestructive evaluation of aircraft composites using transmissive terahertz time domain spectroscopy. Opt Express. 2008;16(21):17039-51.

[32] Jördens C, Scheller M, Wietzke S, Romeike D, Jansen C, Zentgraf T, et al. Terahertz spectroscopy to study the orientation of glass fibres in reinforced plastics. Composites Science and Technology. 2010;70(3):472-7.

[33] Katletz S, Pfleger M, Pühringer H, Mikulics M, Vieweg N, Peters O, et al. Polarization sensitive terahertz imaging: detection of birefringence and optical axis. Opt Express. 2012;20(21):23025-35.

[34] Smith RA, Jones LD, Willsher SJ, Marriott AB. Diffraction and shadowing errors in $-6 \mathrm{~dB}$ defect sizing of delaminations in composites. Insight-Non-Destructive Testing and Condition Monitoring. 1998;40(1):44-9.

[35] Margetan FJ, Leckey CA, Barnard D. Modeling the effects of beam size and flaw morphology on ultrasonic pulse/echo sizing of delaminations in carbon composites. AIP Conference Proceedings. 2013;1511:955-62.

[36] Brucherseifer M, Haring Bolivar P, Klingenberg H, Kurz H. Angle-dependent THz tomography - characterization of thin ceramic oxide films for fuel cell applications. 
Applied Physics B. 2001;72(3):361-6.

[37] Guillet JP, Recur B, Frederique L, Bousquet B, Canioni L, Manek-Hönninger I, et al. Review of Terahertz Tomography Techniques. J Infrared Milli Terahz Waves. 2014;35(4):382-411.

[38] Wietzke S, Jördens C, Krumbholz N, Baudrit B, Bastian M, Koch M. Terahertz imaging: a new non-destructive technique for the quality control of plastic weld joints2007.

[39] Schwerdtfeger M, Castro-Camus E, Krügener K, Viöl W, Koch M. Beating the wavelength limit: three-dimensional imaging of buried subwavelength fractures in sculpture and construction materials by terahertz time-domain reflection spectroscopy. Applied Optics. 2013;52(3):375-80.

[40] Cunningham PD, Valdes NN, Vallejo FA, Hayden LM, Polishak B, Xing-Hua Z, et al. Broadband terahertz characterization of the refractive index and absorption of some important polymeric and organic electro-optic materials. Journal of Applied Physics. 2011;109(4):043505. 


\section{Figure captions}

Fig. 1. (a) Typical optical micrograph of the in-plane section of the eight-harness-stain fabric glass fiber-reinforced polyetherimide matrix laminate; (b) Schematic diagram of samples indicating dimensions.

Fig. 2. Schematic diagram of $\mathrm{THz}$ time-domain spectroscopy (TDS) system in both reflection and transmission.

Fig. 3. (a) $\mathrm{THz}$ reflection $\mathrm{C}$-scan image across $50 \mathrm{~mm}$ x $50 \mathrm{~mm}$ region of sample 1 using the contrast mechanism associated with the peak-to-valley difference of the reflected $\mathrm{THz}$ pulse within the time window 13 ps to $20 \mathrm{ps}$. (b) $\mathrm{THz} \mathrm{C}$-scan image after applying $50 \%$ rule for sizing the delaminations.

Fig. 4. (a) and (b) show $\mathrm{THz}$ reflection B-scan images through the two yellow delaminations appearing in Fig. 3(a). The vertical direction corresponds to the depth direction in the sample. The $\mathrm{THz}$ field is polarized in the vertical direction in all figures.

Fig. 5. Three-dimensional THz images for sample 1. [the $x$ position is not indicated]

Fig. 6. Time traces of detected reflected THz signal (time-dependent electric field) (a) in the absence of delamination, (b) with delamination. The boundaries between various 
colors highlight the reflections associated with various interfaces between the lamina.

Fig. 7. THz reflection images of representative samples corresponding to the results in Table 1. THz C-scans (a1) to (a6), B-scans (b1) to (b6), and time-domain waveforms (c1) to (c6) corresponding to sample $23,10,60,46,51$, and 57 , respectively.

Fig. 8. Ultrasonic imaging C-scan results for samples 51 and 57. (a) 51 in transmission, (b) 57 in transmission, (c) 51 in reflection, and (d) 57 in reflection modes.

Fig. 9. Ultrasonic time domain waveforms without and with delamination for sample 51 in (a) transmission mode and (b) reflection mode.

Fig. 10. Results of sizing the delaminations with $50 \%$ rule corresponding to the ultrasonic C-scan images in Fig.9. (a) 51 in transmission, delamination area $=39.56$ $\mathrm{mm}^{2}$, (b) 57 in transmission, delamination area $=106.81 \mathrm{~mm}^{2}$, (c) 51 in reflection, delamination area $=35.20 \mathrm{~mm}^{2}$, (d) 57 in reflection, delamination area $=122.19 \mathrm{~mm}^{2}$.

Fig. 11. Ultrasonic B-scan images for (a) 51 with $x$ position at $18 \mathrm{~mm}$, (b) 57 with $x$ position at $18 \mathrm{~mm}$. 
(a)

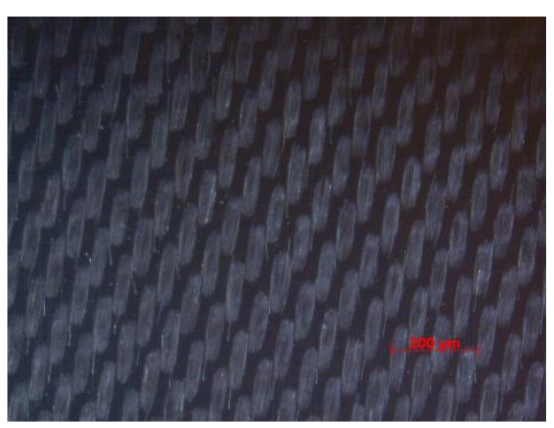

(b)

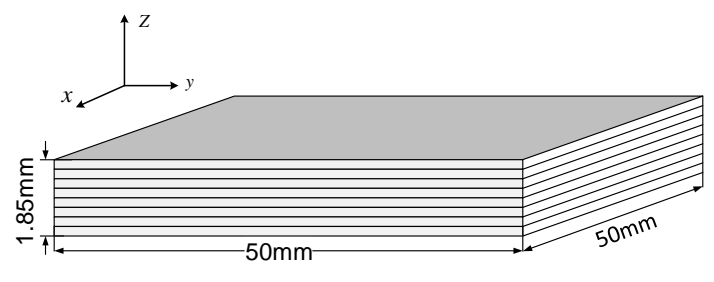

Fig. 1. (a) Typical optical micrograph of the in-plane section of the eight-harness-stain fabric glass fiber-reinforced polyetherimide matrix laminate; (b) Schematic diagram of samples indicating dimensions. 


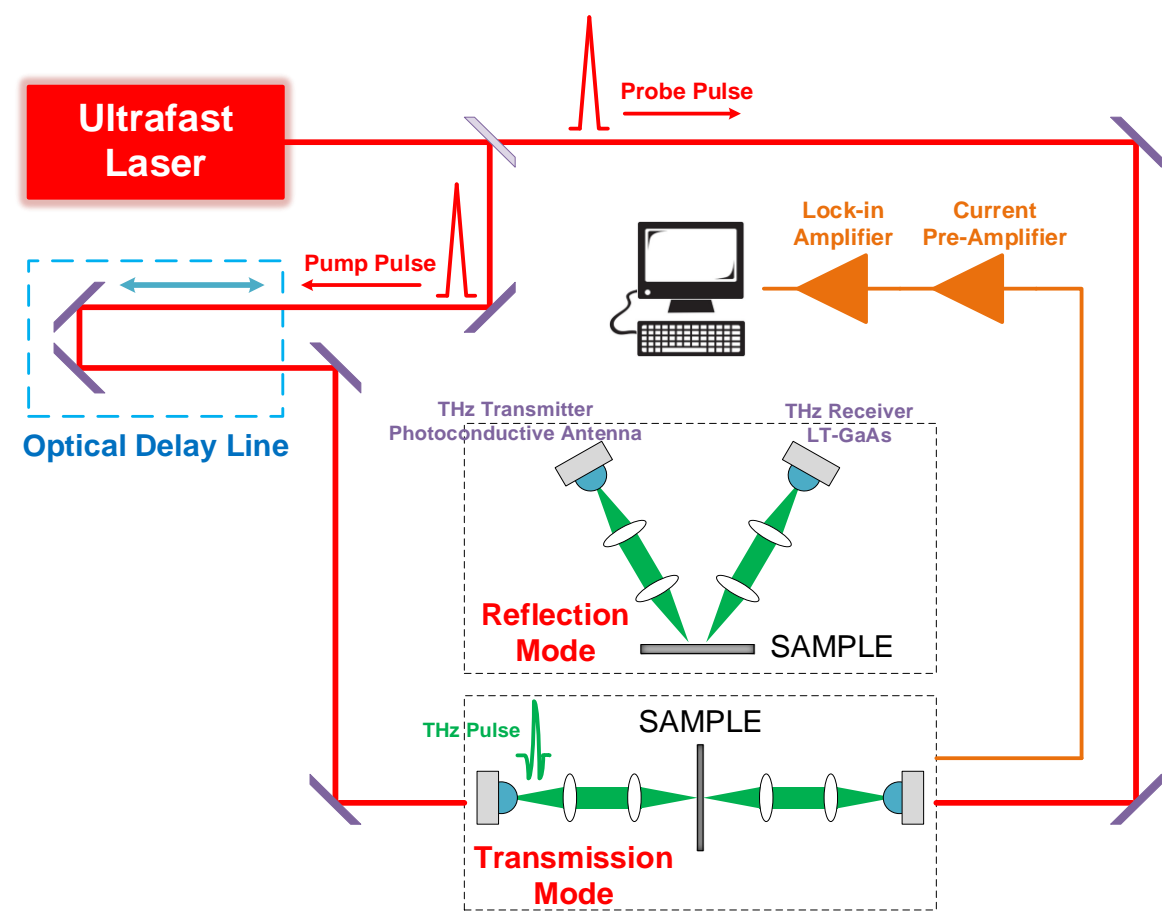

Fig. 2. Schematic diagram of $\mathrm{THz}$ time-domain spectroscopy (TDS) system in both reflection and transmission. 

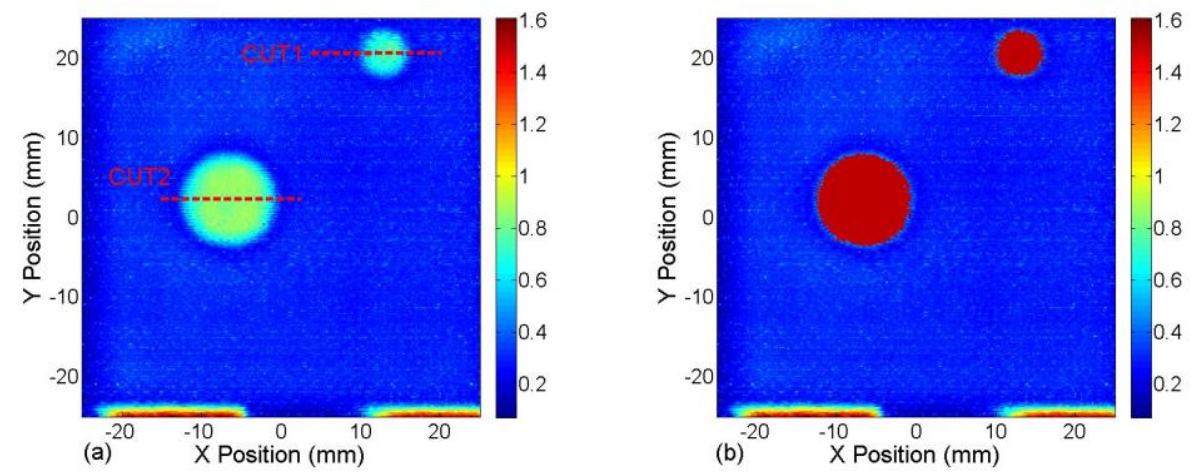

Fig. 3. (a) $\mathrm{THz}$ reflection $\mathrm{C}$-scan image across $50 \mathrm{~mm}$ x $50 \mathrm{~mm}$ region of sample 1 using the contrast mechanism associated with the peak-to-valley difference of the reflected $\mathrm{THz}$ pulse within the time window 13 ps to 20 ps. (b) $\mathrm{THz} \mathrm{C}$-scan image after applying $50 \%$ rule for sizing the delaminations. 

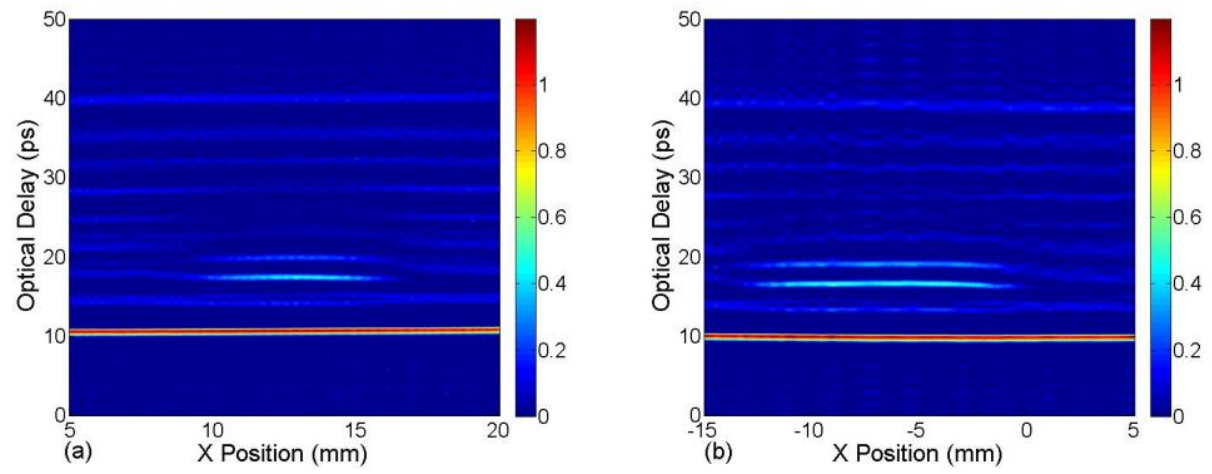

Fig. 4. (a) and (b) show $\mathrm{THz}$ reflection B-scan images through the two yellow delaminations appearing in Fig. 3(a). The vertical direction corresponds to the depth direction in the sample. The $\mathrm{THz}$ field is polarized in the vertical direction in all figures. 


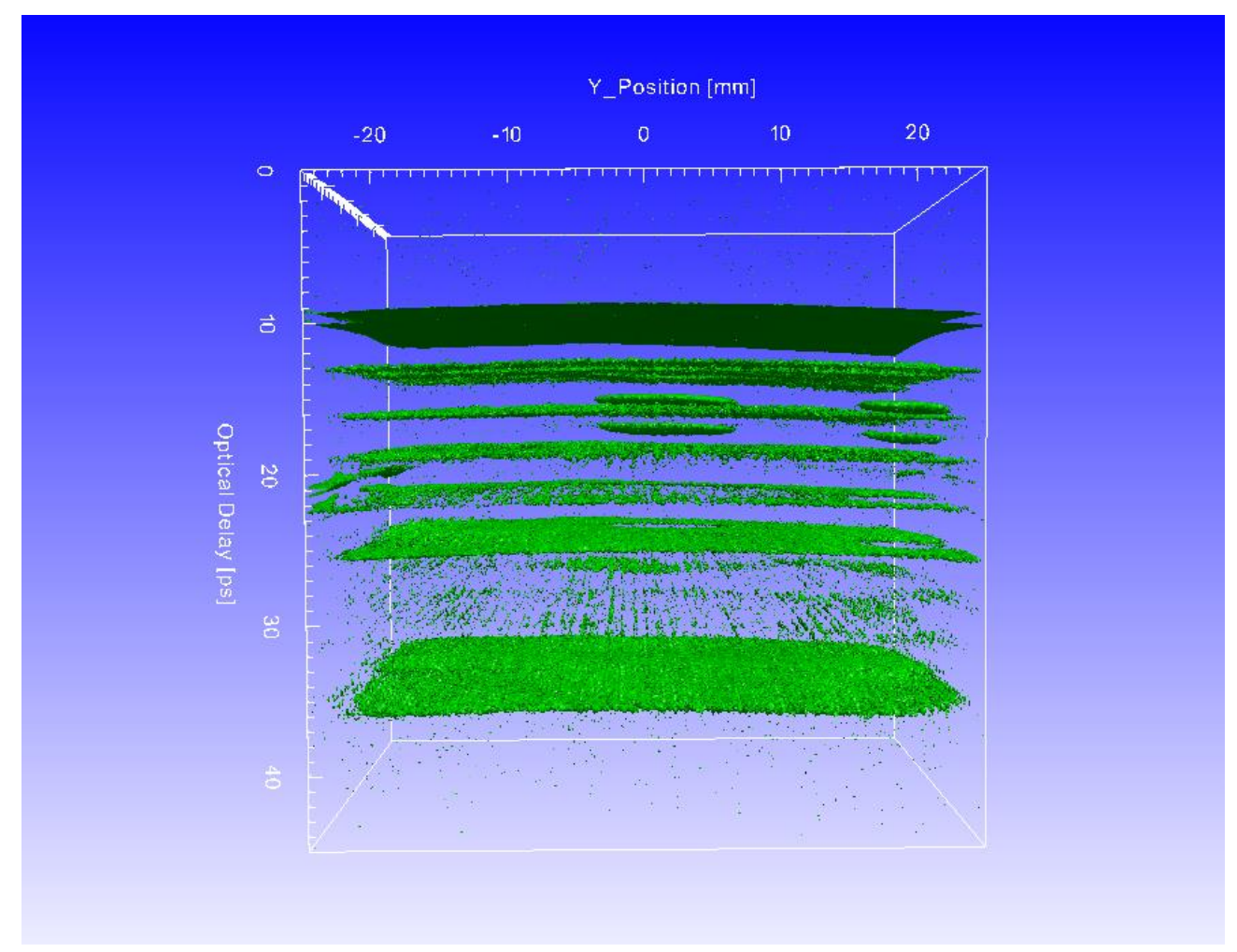

Fig. 5. Three-dimensional $\mathrm{THz}$ images for sample 1. [the $\mathrm{x}$ position is not indicated] 


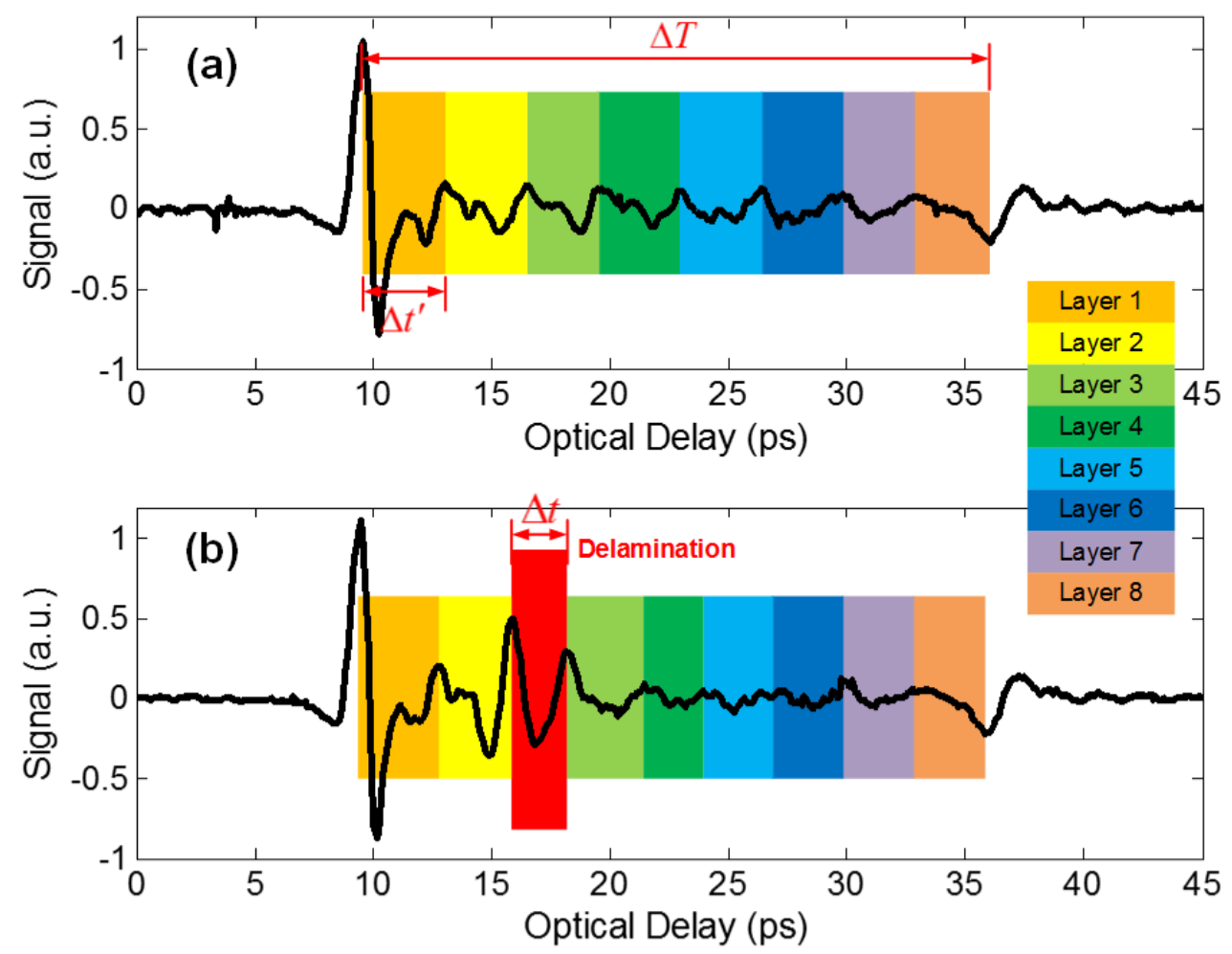

Fig. 6. Time traces of detected reflected THz signal (time-dependent electric field) (a) in the absence of delamination, (b) with delamination. The boundaries between various colors highlight the reflections associated with various interfaces between the lamina. 

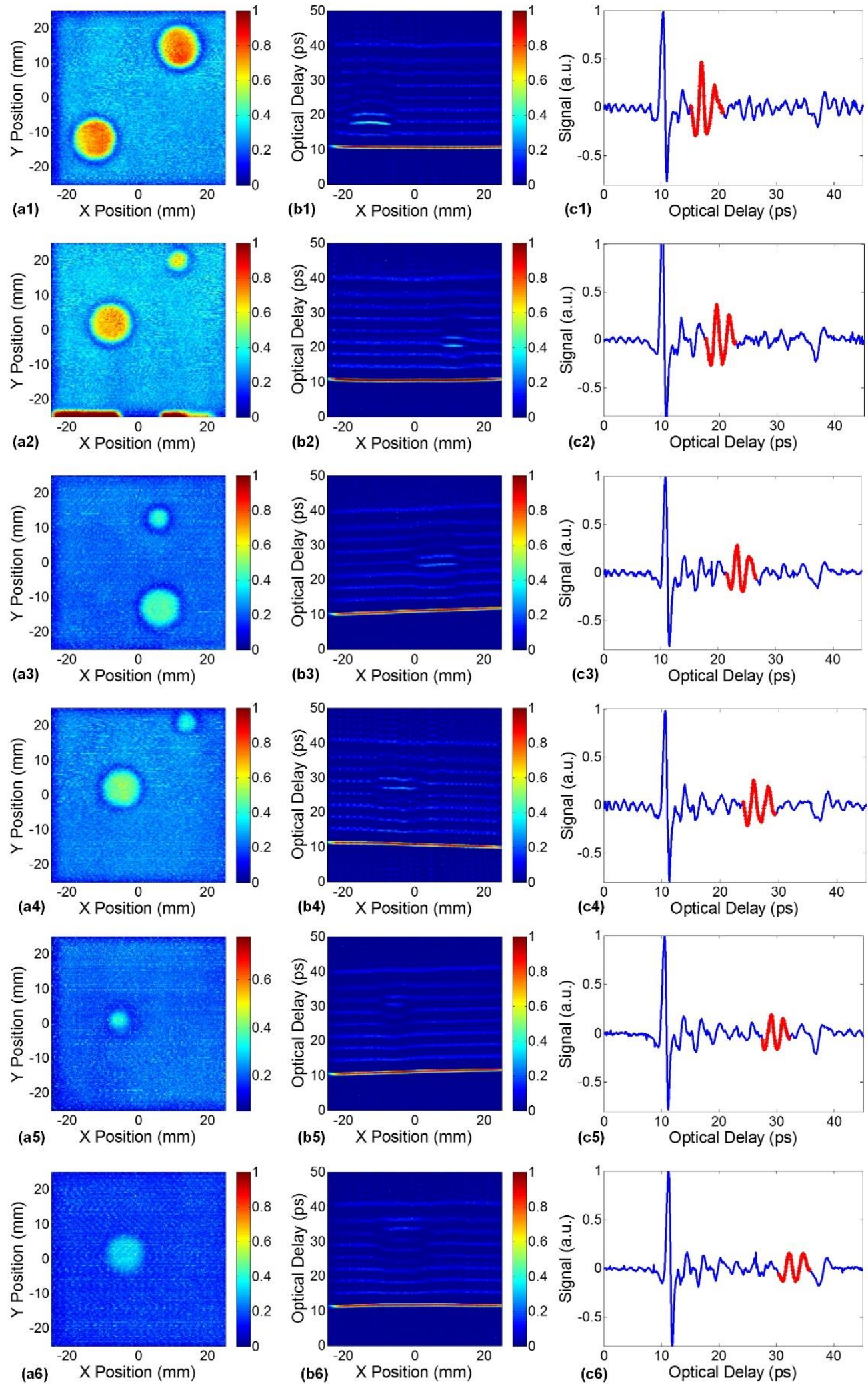
Fig. 7. THz reflection images of representative samples corresponding to the results in Table 1. THz C-scans (a1) to (a6), B-scans (b1) to (b6), and time-domain waveforms (c1) to (c6) corresponding to sample $23,10,60,46,51$, and 57 , respectively. 


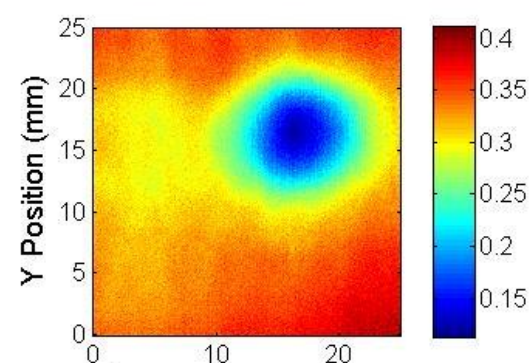

(a) X Position (mm)

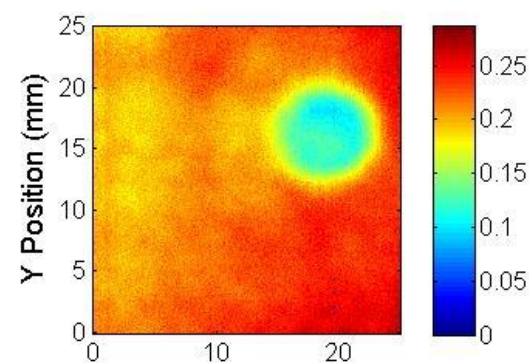

(c) X Position (mm)

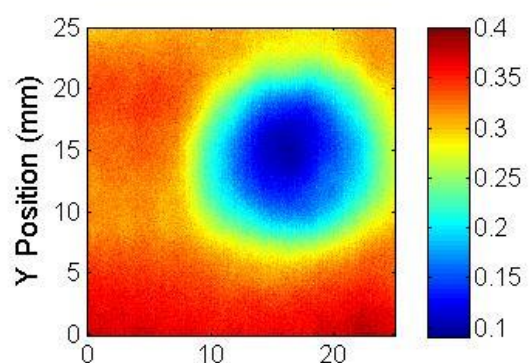

(b) X Position (mm)

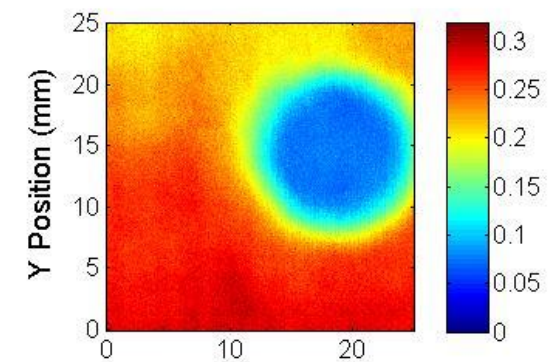

(d) X Position ( $\mathrm{mm})$

Fig. 8. Ultrasonic imaging C-scan results for samples 51 and 57. (a) 51 in transmission,

(b) 57 in transmission, (c) 51 in reflection, and (d) 57 in reflection modes. 

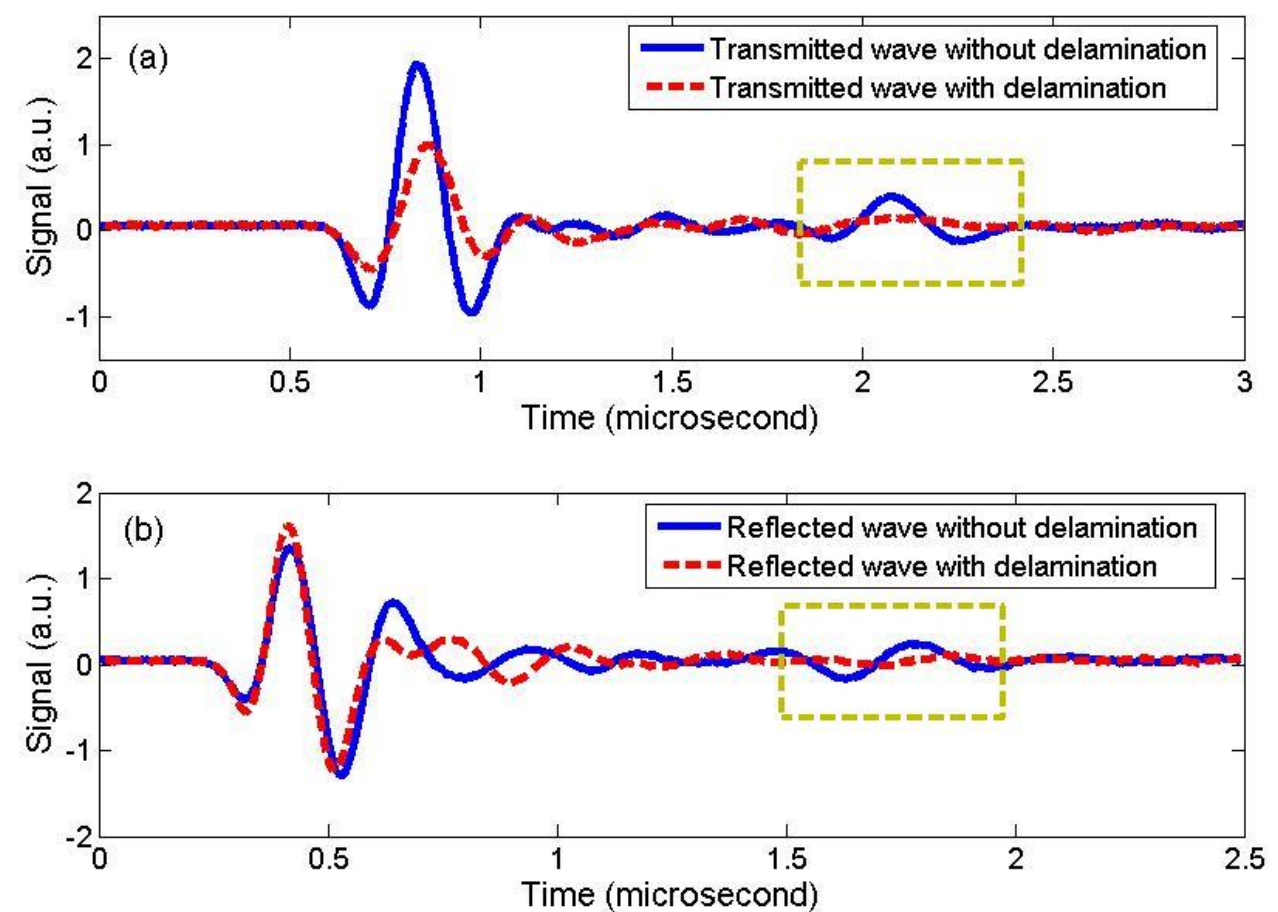

Fig. 9. Ultrasonic time domain waveforms without and with delamination for sample 51 in (a) transmission mode and (b) reflection mode. 


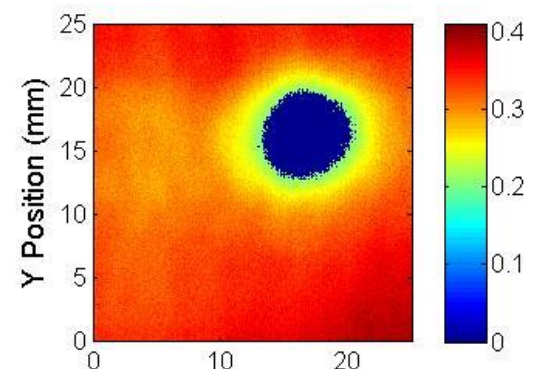

(a) X Position (mm)

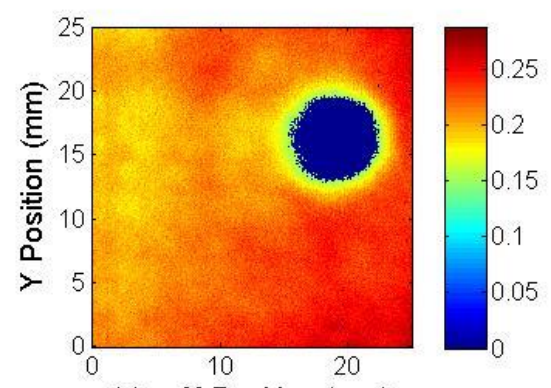

(c) X Position (mm)

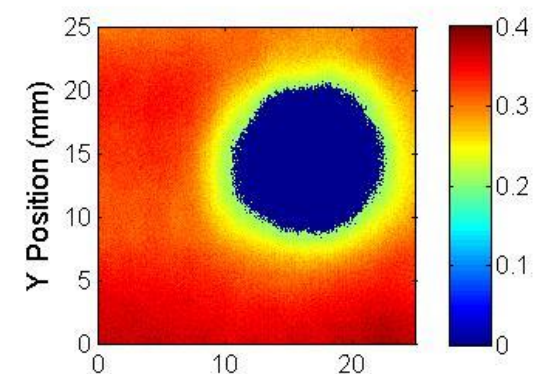

(b) X Position (mm)

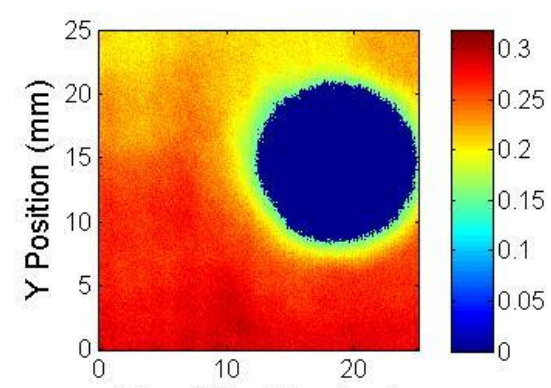

(d) X Position ( $\mathrm{mm})$

Fig. 10. Results of sizing the delaminations with $50 \%$ rule corresponding to the ultrasonic C-scan images in Fig.9. (a) 51 in transmission, delamination area $=39.56$ $\mathrm{mm}^{2}$, (b) 57 in transmission, delamination area $=106.81 \mathrm{~mm}^{2}$, (c) 51 in reflection, delamination area $=35.20 \mathrm{~mm}^{2}$, (d) 57 in reflection, delamination area $=122.19 \mathrm{~mm}^{2}$. 

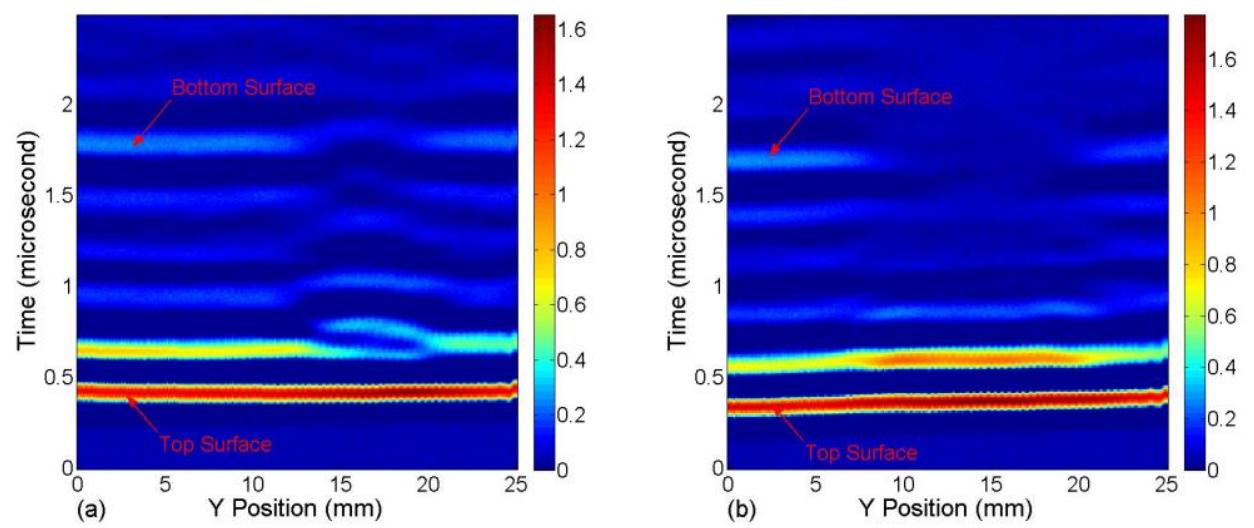

Fig. 11. Ultrasonic B-scan images for (a) 51 with $x$ position at $18 \mathrm{~mm}$, (b) 57 with $x$ position at $18 \mathrm{~mm}$. 